Pferdeklinik

der Vetsuisse-Fakultät Universität Zürich

Direktor: Prof. Dr. Jörg A. Auer, MS, Dipl. ACVS, ECVS

Arbeit unter Leitung von PhD Dr. Michael A. Weishaupt

\title{
Evaluation of skin sensitivity after shock wave treatment in horses
}

\author{
Inaugural-Dissertation \\ zur Erlangung der Doktorwürde der \\ Vetsuisse-Fakultät Universität Zürich \\ vorgelegt von \\ Nina Waldern \\ Tierärztin \\ von Karlsruhe, Deutschland \\ genehmigt auf Antrag von \\ PD Dr. Christoph J. Lischer, Referent \\ Prof. Dr. Hans Geyer, Korreferent
}

Zürich 2005 


\section{Evaluation of skin sensitivity after shock wave treatment in horses}

Nina M. Waldern, med vet; Michael A. Weishaupt, Dr med vet, PhD; Isabel Imboden, med vet; Thomas Wiestner, El Ing HTL; Christoph J. Lischer, Dr med vet

\begin{abstract}
Objective-To evaluate the effects of shock wave treatment on cutaneous nerve function, compared with the effects of local nerve block and sedation.

Animals-18 clinically sound Swiss Warmbloods.

Procedure-Horses were randomly allocated to 3 groups and received different amounts and types of shock waves (extracorporeal shock wave treatment [ESWT] or radial pressure wave treatment [RPWT]). Horses were sedated with xylazine and levomethadone. Shock waves were applied to the lateral palmar digital nerve at the level of the proximal sesamoid bones on 1 forelimb. Skin sensitivity was evaluated by means of an electrical stimulus at the coronary band before and 5 minutes after sedation and at 4, 24, and 48 hours after application of ESWT or RPWT. On the contralateral forelimb, skin sensitivity was tested before and 10 minutes after an abaxial sesamoid nerve block.
\end{abstract}

Results-No significant changes in skin sensitivity were detected, regardless of the shock wave protocol applied. Mean reaction thresholds after sedation were more than twice the baseline thresholds. After the abaxial sesamoid block, no reaction was recorded in any of the horses.

Conclusions and Clinical Relevance-Application of ESWT or RPWT to the palmar digital nerve had no effect on cutaneous sensation distal to the treated region for at least 2 days after application. The analgesic effect of sedation on reaction to electrical stimuli was distinct but varied among horses. ( $A m \mathrm{~J}$ Vet Res 2005;66:2095-2100)

Focused extracorporeal shock wave treatment $F$ (ESWT) and radial pressure wave treatment (RPWT) have been used in the management of a variety of conditions for many years. The discovery that the application of high-energy shock waves led to immediate relief from pain was made by chance during use of the modality in lithotripsy and during treatment for nonunion of bone in humans. ${ }^{1}$ Further observations have confirmed this effect in a number of orthopedic procedures in humans ${ }^{2}$ and horses. ${ }^{3,4}$

Shock waves are high-energy pressure waves characterized by a rapid rise in pressure (to a maximum of nearly 500 bar) followed by a rapid decrease in pres-

\section{Received February 23, 2005.}

Accepted April 18, 2005.

From the Equine Hospital, Vetsuisse Faculty, University of Zurich, CH-8057 Zurich, Switzerland.

Supported by the German Academic Exchange Service (DAAD) and grant 973.256 of the Swiss Federal Veterinary Office (FVO).

The authors thank Alessandra Stoll and Beatus Bächi for technical assistance.

Address correspondence to Dr. Weishaupt. sure and a phase of subpressure known as the tensile wave. The highest concentration of energy can be focused on discrete sites in the body. Recently, RPWT has been introduced as an alternative to ESWT. These pressure waves are transmitted radially, decreasing in energy in proportion to the square of the distance to the surface. ${ }^{5}$

The mechanism by which ESWT and RPWT induce an analgesic effect is unclear. As a result of observations that brief, intense, somatic stimulation may lead to prolonged periods of pain relief, ${ }^{6}$ gate control (ie, inhibition of presynaptic spinal neurons) and hyperstimulation analgesia (ie, activation of descending inhibitory systems) have been suggested ${ }^{7}$ as possible mechanisms of action. However, results of studies ${ }^{8-11}$ to confirm these theories have been contradictory and it remains unclear whether stimulation of an area with ESWs or RPWs activates endogenous nociceptive or antinociceptive mechanisms at all.

Another possibility regarding the mechanism of analgesic effect of ESWs and RPWs involves a direct effect on nerves. The ability of ESWs to generate action potentials in the sciatic nerve of frogs in vitro has been reported, ${ }^{12}$ whereas in other investigations ${ }^{13}$ focused ultrasound waves, which are physically similar to those generated by ESWs and RPWs, induced a reversible block of the treated nerves. Some clinicians feel that the short-term analgesic effect of ESWT and RPWT results from reversible interruption of nerve conductivity. In human patients, application of 50 to 500 shock wave pulses induces an effect similar to that of local infiltative anesthesia that lasts for 15 minutes to 24 hours. ${ }^{14}$ Those investigators suggested that there is inhibition of nerve conduction in cutaneous nerves that are near the treatment site. Nevertheless, at present, there are no objective data that confirm the appearance or duration of the presumed analgesic effect after ESWT or RPWT in horses.

Because a post-treatment analgesic effect could mask pain caused by certain orthopedic diseases, ESWT and RPWT are among the mechanical doping procedures prohibited by the Federation Equine International. ${ }^{15}$ The required withdrawal time between shock wave treatment and participation in a competition is currently 5 days at international equestrian events, an interval that was determined on the basis of empiric data and subjective opinion. In contrast to the increasingly efficient detection of chemical substances, the use of ESWT or RPWT cannot be detected via routine screening tests. There is a need for reliable detection methods to guarantee animal welfare and fairness in equine competitive sports.

After direct application of ESWs or RPWs to a nerve, sensitivity of the supplied skin area may change 
in 1 of 4 ways: complete insensitivity to electrical stimulation, decreased sensitivity, increased sensitivity, or no change in sensitivity. A finding of complete insensitivity would indicate that there was a conductive block of the entire nerve bundle, an effect which might be reversible in hours or days, or more severe axonal damage, in which case several months would be required for recovery of normal sensation. An increase in the stimulation threshold would indicate partial nerve damage (eg, from local demyelinization or ischemia). Increased sensitivity would result from the horse becoming conditioned to the repetitive stimulation. Apart from providing a possible explanation for the analgesic effect of ESWT and RPWT, characteristic changes in skin sensitivity might serve as a method for detecting previous treatment with ESWT or RPWT.

The objective of this study was to evaluate cutaneous nerve function by means of electrical stimulation of the skin at a site distal to a section of nerve treated with ESWs or RPWs. Results were compared with the effects of an abaxial nerve block at the same site on the contralateral limb and with the effect of sedation with a combination of intravenously administered xylazine and levomethadone.

\section{Materials and Methods}

Animals-Eighteen Swiss Warmbloods ${ }^{a}(15$ geldings and 3 mares) with a mean age of 6.9 years (range, 4 to 14 years) and a mean body weight of $568 \mathrm{~kg}$ (range, 540 to $630 \mathrm{~kg}$ ) were used in the study. Horses were judged to be clinically sound on the basis of physical examination findings; evaluation of the gait at the walk and trot; flexion tests of all 4 limbs; and palpation of the limbs for heat, swelling, or signs of pain. Horses were housed in box stalls and fed a ration of concentrates and ad libitum hay. After the testing procedures, horses were exercised daily for approximately 45 minutes on a horse-walker or treadmill. Hair was clipped to a uniform length from above the metacarpophalangeal (ie, fetlock) joint to the coronary band in both forelimbs $\geq 24$ hours before the experiment to ensure uniform testing conditions among horses for the skin sensitivity test.

Experimental protocol-Skin sensitivity was tested by use of electrical stimulation before performing the abaxial sesamoid block (A0) and 10 minutes after the block (A1) The abaxial sesamoid nerve block ${ }^{16}$ was performed with $2 \mathrm{~mL}$ of $2 \%$ mepivacaine ${ }^{b}$ on a randomly chosen forelimb. Success of the nerve block was assessed by means of mechanical stimulation with a blunt object. On the following day, baseline measurements (T0) were made on the contralateral limb. The horse was sedated (xylazine, ${ }^{\mathrm{c}} 0.35$ $\mathrm{mg} / \mathrm{kg}$, IV, and levomethadone, ${ }^{\mathrm{d}} 44 \mu \mathrm{g} / \mathrm{kg}, \mathrm{IV}$ ) and skin sensitivity was reevaluated 5 minutes later $\left(\mathrm{T}_{\text {sed }}\right)$; ESWT or RPWT was performed and the sensitivity tests were repeated 4 (T4), 24 (T24), and 48 (T48) hours after treatment. To evaluate the time independence of the baseline reaction thresholds, skin sensitivity tests on the same limb were repeated $>2$ months after the first evaluation in 11 horses. In 1 horse, the treated region was imaged with ultrasound 1 day after ESWT (2,000 pulses). The experimental protocol was approved by the Animal Health and Welfare Commission of the canton of Zurich.

Shock wave treatment-Horses were randomly allocated into 3 groups. Horses in each group received a different treatment regarding the number, energy level, and type of shock wave pulses (ESW or RPW). The skin was thoroughly cleansed with soap and water and degreased with alcohol. Ultrasonic coupling gel was applied before treatments to ensure optimal transmission of energy. Shock waves were applied over the palmar digital nerve on the abaxial surface of the lateral sesamoid bone on the forelimb that had not been used for the nerve block the day before. In each treatment group, an equal number of left and right limbs was treated. Two groups were treated with focused shock waves delivered by an electrohydraulic shock wave generator ${ }^{e}$ with a $5-\mathrm{mm}$ transducer at a pulse rate of 240 pulses/min and an energy level of $0.15 \mathrm{~mJ} / \mathrm{mm}^{2}$. Horses in the first group (ESWT 1,000 ) received 1,000 pulses, and horses in the second group (ESWT 2,000) received 2,000 pulses. Horses in the third group (RPWT 2,000) received 2,000 pulses delivered by a pneumatic shock wave generator with a $15-\mathrm{mm}$ applicator at a mean pressure of $2.5 \mathrm{bar}$ and an energy level of $0.14 \mathrm{~mJ} / \mathrm{mm}^{2}$. These energy settings and pulse numbers of ESWT and RPWT are commonly used in the treatment of equine orthopedic diseases. ${ }^{4,17,18}$

Evaluation of skin sensitivity-Skin sensitivity was determined by use of electrical stimulation to ensure application of a defined and reproducible stimulus. Topographic features of distal limb skin innervation in horses are such that certain areas on the palmar aspect of the medial or lateral side of the heels ${ }^{19.22}$ are those most likely to receive innervation solely from the palmar digital nerve. For practical reasons, the lateral side was chosen for stimulation. The skin above the coronary band was stimulated with 2 surface electrodes (diameter, $4 \mathrm{~mm}$; inter-electrode distance, $10 \mathrm{~mm}$ ) with a prismatically grooved contact surface ${ }^{\mathrm{g}}$ (active area, $26 \mathrm{~mm}^{2}$ each). The 2 pin electrodes were electrically isolated and mounted on an S-shaped metal spring. This device was affixed to a small $(18 \times 9-\mathrm{mm})$ metal plate that was glued to the lateral hoof wall with polymerizing vacuum glue." The electrode support was affixed such that the electrode pins exerted a subjectively controlled constant force of approximately $2 \mathrm{~N}$ on the skin (Figure 1). The exact position of the electrode was marked with a permanent pen to allow precise placement for repeated investigations. The 2

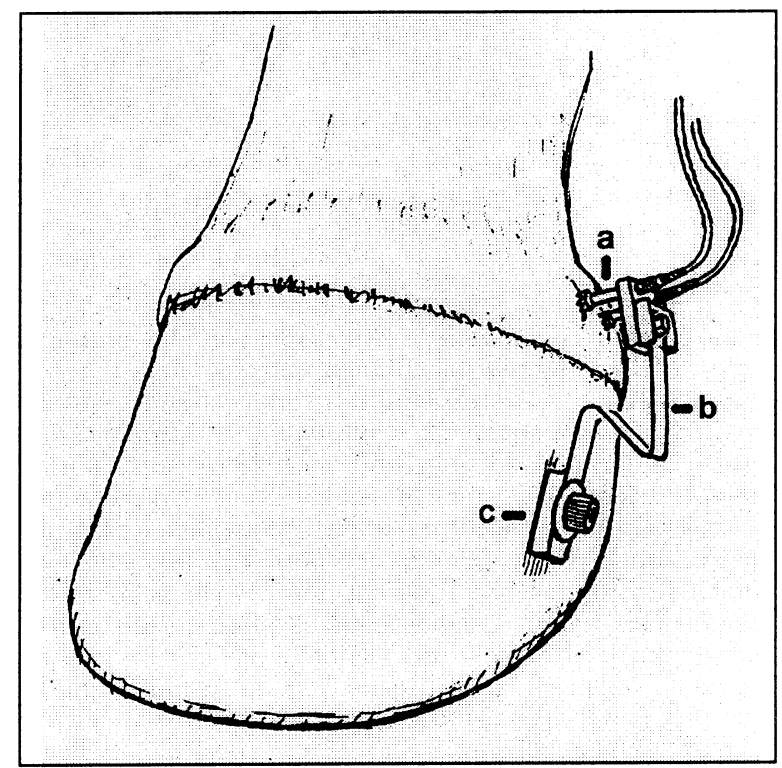

Figure 1-Illustration of the device used to deliver electrical stimulation to the skin of the coronary band of horses that had shock wave treatment of the lateral palmar digital nerve. The device consists of 2 pin electrodes (a) mounted on an S-shaped metal spring (b) and affixed to a metal plate (c) glued to the hoof wall. 
wires leading to the stimulus voltage generatori were attached to the horse's limb with straps. One stimulation consisted of a burst of 3 rectangular electrical pulses (duration, 2 milliseconds) with pulse intervals of 40 milliseconds. The stimulation was triggered manually.

Four types of corporeal reactions were observed and classified: restlessness or uneasiness, muscular reflex, conscious movement of the limb, and turning of the head. The stimulation voltage was increased in $10-\mathrm{V}$ increments until the horse had at least 1 of the reaction types after each of 3 successive stimulations at the same voltage level. This level was defined as the reaction threshold. The time lag between repeated stimulations was longer than 10 seconds. The maximum stimulation voltage applied to the skin after nerve blocking and sedation did not exceed 4 times the baseline voltage, which had been determined previously in the untreated limb.

Statistical analysis-For each horse and reaction type, 3 corporeal reactions were counted per threshold voltage. On the basis of the total number of possible reactions from measurements at times $\mathrm{A} 0, \mathrm{~T} 0, \mathrm{~T} 4, \mathrm{~T} 24$, and $\mathrm{T} 48$, the relative frequency (ie, out of 5 measurements $\times 18$ horses $\times 3$ stimulations) of each reaction type was calculated. The 4 repeated reaction threshold voltages (T0, T4, T24, and T48) determined in each horse were compared by use of a 1-way ANOVA test on ranks. Pairwise multiple comparisons were performed with the Student-Newman-Keuls test to assess the differences among horses.

The baseline reaction thresholds for both forelimbs (T0 and $\mathrm{A} 0 ; \mathrm{n}=18$ horses), of 2 repeated measures on the same limb (11 horses), and before and after sedation (17 horses) were compared by use of paired $t$ tests. To determine the influence of ESWT on cutaneous sensation, a l-way repeated-measures ANOVA was performed with the threshold values of the 4 measurement times for each treatment method in separate tests ( $n=6$ horses). A 2-way repeated-measures ANOVA with data from all 18 horses was performed to test the influences of method and time. On the basis of the intraindividual $\mathrm{SD}$ of repeated measures in each horse $\left(\mathrm{SD}_{\text {intra }}\right)$

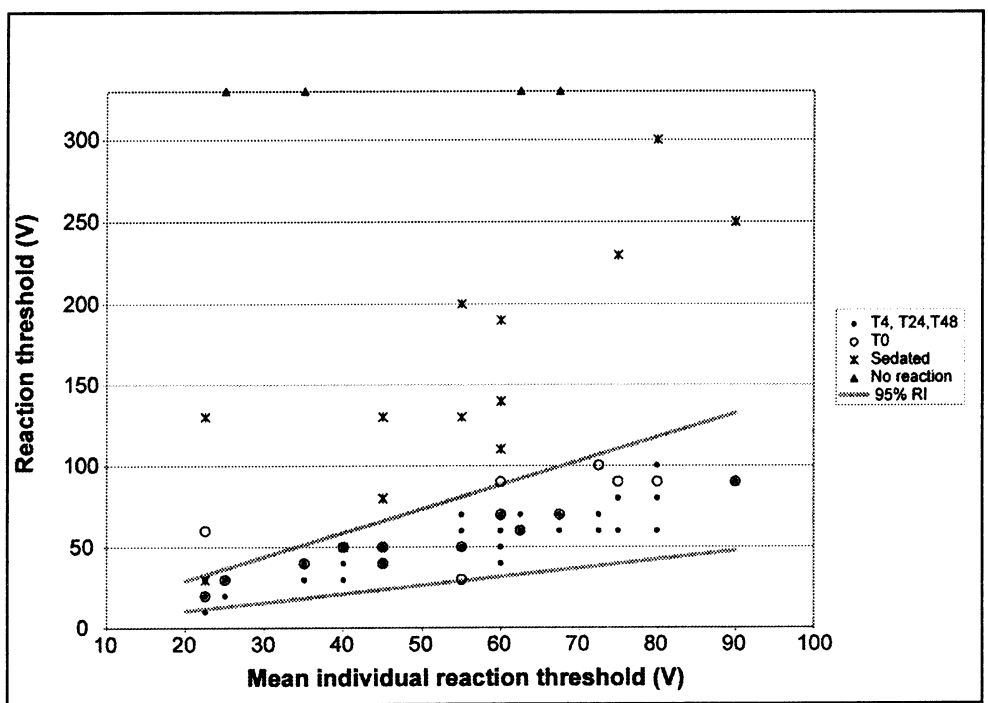

Figure 2-Scatterplot of reaction threshold voltages versus mean individual reaction threshold voltages before and after extracorporeal shock wave treatment or radial pressure wave treatment and after sedation in 18 horses. Four horses showed no reaction after sedation; thier values (fillied triangles) fall outside the range of the $y$-scale. TO $=$ Threshold reaction voltage before shock wave treatment. T4 = Threshold reaction voltage 4 hours after shock wave treatment. T24= Threshold reaction voltage 24 hours after shock wave treatment. T48 = Threshold reaction voltage 48 hours after treatment. $\mathrm{RI}=$ Reference interval. and the quantile of the $t$ distribution (significance level, $\alpha=$ 0.05 degree of freedom $[d f]$ ), a $95 \%$ reference interval (RI) was calculated with $\mathrm{SD}_{\text {intra }} \times \mathrm{t}_{(1-\alpha / 2 ;}$ if). The $\mathrm{SD}_{\text {intra }}$ and $\mathrm{RI}$ were expressed relative to the overall mean threshold (TO to T48) as coefficient of variance (CV) and $\mathrm{RI}_{\text {rel }}$. Values of repeated measurements in the untreated limb of each horse will remain with a probability of $95 \%$ within a range of \pm $\mathrm{RI}_{\mathrm{rel}}$ of the horse's mean individual threshold. Statistical analyses were performed with commercially available software, ${ }^{j}$ and values of $P \leq 0.05$ were considered significant.

\section{Results}

Application of ESWT and RPWT was well tolerated by all horses. No signs of swelling, pain, or hematoma formation were observed at the application site in any of the horses. Ultrasonographic evaluation of the treated region 1 day after shock wave therapy in 1 horse from the ESWT 2,000 group revealed no tissue alterations.

Skin sensitivity test-Horses reacted variably to electrical stimulation. The most frequent reaction was the muscular reflex (ie, muscular twitch or panniculus reflex), which was usually observed in the region of the elbow or shoulder and was seen in $97 \%$ of all stimulations at the reaction threshold. Movements of the limb occurred with a frequency of $27 \%$, and turning of the head was observed in $2 \%$ of the stimulations. Restlessness or uneasiness was not observed.

Horses' mean reaction thresholds at times T0, T4, $\mathrm{T} 24$, and T48 ranged from 22.5 to $90.0 \mathrm{~V}$ and were significantly $(P<0.001)$ different among horses. Mean baseline reaction thresholds between the contralateral limbs (at T0, 60.0 $\pm 25.9 \mathrm{~V}$; at A0, $58.9 \pm 27.2 \mathrm{~V}$ ) were not significantly $(P=0.85)$ different. In the 11 horses in which the baseline reaction threshold of 1 limb was measured twice, the difference of mean thresholds $(10.0 \pm 24.9 \mathrm{~V})$ was not significant $(P=0.21)$

Abaxial sesamoid block-After the nerve block, complete insensitivity of the skin resulted in all horses. No reactions were evoked after stimulation with voltages up to 4 times the baseline threshold voltage (defined as a negative result).

Sedation-The typical signs of sedation with an $\alpha-2$ adrenoceptor agonist (eg, lowering of the head, incoordination of the hind limbs, and sweating) were observed in all horses at the time the stimulation test was started. The data for stimulation with sedation were not available for 1 horse.

In 15 of 17 horses, there was an increase in the reaction threshold (Figure 2); in 4 of those horses, increasing the stimulation voltage up to 4 times the baseline voltage evoked no reaction and no threshold values were available. In the other 2 horses, reaction threshold voltages remained in the $\mathrm{RI}_{\text {rel }}$ (derived from values in the nonsedated horse). Excluding the 4 horses with no measur- 
Table 1-Mean \pm SD threshold voltages for reaction to electric stimulation of coronary band skin after shock wave treatment of the palmar digital nerve via 1 of 3 treatment protocols (ESWT 1,000, ESWT 2,000 , RPWT 2,000). Reaction threshold voltages were determined before and at 4, 24, and 48 hours after treatment. Values were compared with values obtained from stimulation of the skin on the untreated contralateral limb.

\begin{tabular}{|c|c|c|c|c|c|c|c|}
\hline $\begin{array}{l}\text { Shock wave } \\
\text { treatment }\end{array}$ & $\mathbf{n}$ & AO & TO & T4 & T24 & T48 & $P$ value \\
\hline $\begin{array}{l}\text { ESWT 1,000 } \\
\text { ESWT 2,000 } \\
\text { RPWT 2,000 } \\
\text { All methods }\end{array}$ & $\begin{array}{r}6 \\
6 \\
6 \\
18\end{array}$ & $\begin{array}{l}66.7 \pm 17.5 \\
70.0 \pm 28.3 \\
50.0 \pm 37.4 \\
58.9 \pm 27.2\end{array}$ & $\begin{array}{l}56.7 \pm 25.8 \\
61.7 \pm 27.1 \\
61.7 \pm 29.3 \\
60.0 \pm 25.9\end{array}$ & $\begin{array}{l}58.3 \pm 16.0 \\
51.7 \pm 26.4 \\
50.0 \pm 28.3 \\
53.3 \pm 23.0\end{array}$ & $\begin{array}{l}56.7 \pm 10.3 \\
50.0 \pm 23.7 \\
51.7 \pm 27.9 \\
52.8 \pm 20.8\end{array}$ & $\begin{array}{l}53.3 \pm 15.1 \\
48.3 \pm 21.4 \\
48.3 \pm 21.4 \\
50.0 \pm 18.5\end{array}$ & $\begin{array}{l}0.91 \\
0.18 \\
0.32 \\
0.10\end{array}$ \\
\hline \multicolumn{8}{|c|}{$\begin{array}{l}\text { ESWT }=\text { Extracorporeal shock wave treatment. RPWT }=\text { Radial pressure wave treatment. } 1,000 \text { an } \\
2,000=\text { Number of wave pulses delivered. AO }=\text { Threshold reaction voltage performed the previous day on th } \\
\text { contralateral limb. TO }=\text { Threshold reaction voltage before shock wave treatment. T4 }=\text { Threshold reactio } \\
\text { voltage } 4 \text { hours after shock wave treatment. T24 = Threshold reaction voltage } 24 \text { hours after shock wav } \\
\text { treatment. T48 = Threshold reaction voltage } 48 \text { hours after treatment. }\end{array}$} \\
\hline
\end{tabular}

able reaction thresholds while sedated, values for $\mathrm{T}_{\text {sed }}$ $(151.5 \pm 79.1 \mathrm{~V})$ were significantly $(P<0.001)$ higher than the measurements for T0 $(63.1$ $\pm 25.1 \mathrm{~V})$.

ESWT and RPWT-There were no detectable changes in skin sensitivity after treatment with either type of shock wave (Table 1 ). The 2-way repeatedmeasures ANOVA model indicated that neither the treatment method $(P=0.95)$ nor length of time after treatment $(P=0.10)$ had a significant influence on mean reaction threshold voltage. The overall mean \pm SD of all threshold voltages measured before and after ESWT or RPWT at T0, T4, T24, and T48 was $54.0 \pm$ $22.1 \mathrm{~V}$. On the basis of findings from the ANOVA, these measurements were regarded as repeated measures of an untreated limb. The $\mathrm{SD}_{\text {intra }}$ of these repeated measurements was $12.1 \mathrm{~V}(\mathrm{CV}, 23.2 \%)$, resulting in an $\mathrm{RI}_{\text {rel }}$ of $47 \%$, around the mean threshold voltage for each horse (Figure 2).

\section{Discussion}

Our study revealed that the thresholds for reactivity to cutaneous stimulation before and up to 48 hours after application of ESWs or RPWs were not significantly different. The response of horses to cutaneous stimulation was not influenced by the mode of treatment or the number of applied pulses. The overall mean \pm SD voltage required to induce 3 successive reactions to electrical stimulation at the same voltage was $54.0 \pm 22.1 \mathrm{~V}$. However, mean reaction thresholds of the 18 horses ranged from 22.5 to $90.0 \mathrm{~V}$, and those values were significantly different. The mean CV for the repeated measures of each individual (ie, intraindividual variation) was $23.2 \%$. This resulted in a $\mathrm{RI}_{\text {rel }}$ of $47 \%$, indicating that with a $95 \%$ probability, repeated measures from a given horse would lie in the range of $\pm 47 \%$ of the mean reaction threshold. Comparison of reaction thresholds between nontreated contralateral limbs ( $\mathrm{A} 0$ vs $\mathrm{TO}$ ) indicated values that were not significantly different. Trials in humans ${ }^{23}$ have also revealed that values for reaction threshold in both limbs are similar.

Slightly more than half of the overall CV of $41 \%$ (observed between the measurements before and after ESWT or RPWT) was derived from differences resulting from repetition of the measurements (ie, intra-indi- vidual variation, $23.2 \%$ ). The remaining variation was from interindividual variation $(17.8 \%)$ among horses. Interindividual variation is thought to result from differences in the electrical impedance of skin (which may play the major role) as well as from differences in the density of nerve supply and nociceptors in the skin at the stimulation site. The temperament of the horse may also influence the type and intensity of reaction to electrical stimulation. The intra-individual variation in threshold voltage measurements may be caused by changes in impedance at the electrode-skin interface (from slight alterations in contact pressure of the electrodes), varying proximity of the electrodes to neural structures (ie, nerve endings or receptors), and the momentary level of arousal of the horse (ie, relaxed or nervous). To limit the influence of the horses' arousal status, testing was performed in quiet surroundings with minimal external diversions. In experiments with human patients, threshold values up to $50 \%$ higher than expected were obtained when patients were distracted during stimulation. ${ }^{24}$ A possible explanation for this finding may be the psychogalvanic reflex, in which sensory or emotional stimuli induce changes in cutaneous impedance via activation of sweat glands, the efferent pathways of which are sympathetic cholinergic fibers. ${ }^{25}$ Repeated stimulations might also result in habituation ${ }^{26}$ and hence sensitization or desensitization of the horse. In our study, horses' mean reaction threshold voltage decreased from $\mathrm{T} 0$ to $\mathrm{T} 48$, but this trend was not significant.

Similar to our findings, no changes in skin sensitivity were detected in a similar study ${ }^{27}$ that tested skin sensitivity distal to a treated region after ESWT and RPWT (ie, the conductive effect). In another study, ${ }^{28}$ treatment of palmar digital nerves with RPWs resulted in decreased sensory nerve conduction velocities at 3 and 7 days after treatment. A slightly reduced nerve conduction velocity disables neither sensory perception nor induction of motor protection responses, and such findings do not necessarily contradict our results.

Other studies conducted to investigate possible analgesic effects at the site of shock wave application (ie, the infiltrative effect) have yielded conflicting results. Although there was evidence of cutaneous analgesia (as measured by use of electrical stimulation) after ESWs or RPWs were applied at the middle por- 
tion of the third metacarpal bone in 1 study, ${ }^{27}$ those results could not be confirmed after application of RPWs at the same site and use of thermal skin stimulation in the form of a focused light beam in another study. ${ }^{29}$ In a clinical trial in horses with navicular syndrome, no analgesic effect was observed after RPWT. ${ }^{k}$

The absence of significant changes in skin sensitivity after direct treatment of a nerve suggests that cutaneous electrical stimulation is not a suitable method for detecting the application of ESWs or RPWs. In consideration of the metabolic effects attributed to ESWT and RPWT, ${ }^{30}$ thermographic testing methods might represent another possibility for detection of changes associated with shock wave treatment. Such methods have been used successfully in the detection of performance-enhancing procedures, such as perineural injections or neurectomy in horses. ${ }^{31,32}$ However, in a study ${ }^{33}$ in which ESWT was applied to the origin of the suspensory ligament, no significant changes in thermal patterns in the treated region were observed.

Different stimulation methods have been described in investigations of cutaneous nociception in horses, ${ }^{34}$ including electrical stimuli, ${ }^{35-37}$ mechanical pressure, 35,36 and thermal stimuli (eg, a focused light beam) ${ }^{29,38}$ Skin sensitivity testing by means of electrical stimulation was used in our study because it was easy to apply and yielded reproducible, quantifiable results that were suitable for assessment of cutaneous nerve function. Similar methods have been used successfully in humans ${ }^{23,24}$ and horses. ${ }^{35,37,39}$

In our study, increments of $10 \mathrm{~V}$ were used to limit the number of stimulations required to elicit a positive response and to minimize habituation effects. To prevent a learning effect, no audible or visible events accompanied the triggering of the stimulus. The electrical stimuli were delivered when horses were standing such that there was equal distribution of weight among all 4 limbs to avoid modification of the elicited limb reflex. Stimulation of nonsedated horses was only carried out if the horse was calm and attentive.

It could be argued that electrical stimulation by means of constant voltage contributed to the variability in the data. In our testing setup, application of the electrodes to dry skin in the absence of coupling gel resulted in high impedance (several kilo ohm) at the electrode-skin interface. Thus, the effective current into the tissue was nearly independent of alterations in skin impedance. Consequently, the overall reaction threshold variation of $41 \%$ was comparable $e^{35}$ to or lower $^{36}$ than CVs from studies in which constant-current stimulation was used.

A conductive nerve block of the palmar digital nerve at the level of the sesamoid bones results in a characteristic desensitization pattern of the skin and deeper structures from the fetlock distally. A wedge-shaped area on the dorsal surface of the fetlock and pastern generally remains unaffected. ${ }^{40}$ Supplementary innervation of the skin on the lateral and medial sides via the palmar metacarpal nerves or the ulnar nerve has been described; however, most authors agree that those areas are usually desensitized by a palmar digital nerve block.
Consistent with those findings, complete insensitivity of the skin to electrical stimuli at the lateral hind quarter of the coronary band was observed in our study and confirmed that there was single nerve supply at the stimulation site in all horses.

After sedation, the mean reaction threshold was more than twice as high as the threshold in the nonsedated state. However, horses responded differently to sedation: in 4 horses, no reaction was evoked when a voltage 4 times as high as the baseline voltage was applied, whereas in 2 horses, there was no alteration of the reaction threshold after sedation (Figure 2). The degree of sedation as assessed visually was similar in all horses and was characterized by the head being held at a position below the level of the withers. This head position is recognized as a characteristic measure of the depth of sedation. ${ }^{37}$ Similar results have been obtained in other studies in which constant-current electrical stimulation of coronary band skin was used to evaluate skin sensitivity before and after sedation. Sedation with xylazine alone at a dose of $1.1 \mathrm{mg} / \mathrm{kg}$ nearly doubled the mean reaction threshold 15 minutes after injection in 1 study. ${ }^{35}$ Administration of a combination of detomidine and an opioid led to reaction thresholds that were nearly 5 times the baseline level in another study. ${ }^{36}$ Antinociceptive thresholds reported in a study ${ }^{35}$ that used constant-current stimulation indicated that there was considerable variability $(\mathrm{CV}, 47 \%)$ after sedation, similar to values for $\mathrm{CV}(52 \%)$ in our horses. These variations could be a result of the influence of the horse's mental state on the effectiveness of the sedative and the degree of analgesia. Sedation has a more potent effect on calm animals, whereas agitated horses or those of nervous disposition are affected less. ${ }^{41}$

Our observations suggest that sedation with xylazine and levomethadone had an antinociceptive effect. These results should be regarded with caution when interpolated to a clinical situation because there may be differences among horses in tolerance to different nociceptive stimuli (ie, electrical vs mechanical). ${ }^{35,36}$ We hypothesized that these differences could be attributed to variation in the distribution of $\alpha_{2}$-adrenergic receptor subtypes in the neural circuitry involved in responses to the different types of nociceptive stimuli. ${ }^{42}$

To answer the question of whether our model was able to detect alterations in cutaneous nociception after the application of ESWs or RPWs on the palmar digital nerve, the reaction thresholds after sedation and anesthesia were determined. Those values represented the possible extremes of a hypothesized influence of ESWT and RPWT. No cutaneous analgesia was observed at sites distal to the shock wave-treated section of the palmar digital nerve. The reaction thresholds remained markedly lower than those observed after sedation and within the range of values for the nontreated nerve. We conclude that ESWT and RPWT do not interfere with nerve conductivity or affect functional integrity.

\footnotetext{
a. Provided by Dr. Beat Wampfler and the Swiss National Equestrian Center Berne, Berne, Switzerland.

b. Mepivacain-adrenalin 2\%, G Streuli and Co AG, Uznach, Switzerland.

c. Xylazin Streuli, G Streuli and Co AG, Uznach, Switzerland

d. l-Polamivet, Intervet, Veterinaria AG, Zurich, Switzerland.
} 
e. Equitron, High Medical Technologies, Lengwil, Switzerland.

f. Electro Medical Systems, Swiss Dolor Clast Vet, Switzerland.

g. Contact Products Inc, Pomona, Calif.

h. Ergo 5713 (cyanacrylate), Kisling AG, Tagelswangen, Switzerland.

i. DISA Typ 9014E, Dantec, Denmark.

j. SigmaStat, SPSS Inc, Chicago, Ill

k. Brown KE, Nickels FA, Robinson RL, et al. Short-term analgesic effect of extracorporeal shock wave therapy in horses with navicular syndrome (abstr). Equine Comp Exerc Physiol 2004;1:A4

\section{References}

1. Dahmen GP, Meiss L, Nam VC. Extrakorporale Stosswellentherapie (ESWT) im knochennnahen Weichteilbereich an der Schulter. Extr Orthop 1992;11:25-27.

2. Rompe JD. Shockwave therapy: therapeutic effects in a speculative mechanism [in German]. Z Orthop Ihre Grenzgeb 1996;134:13-19.

3. Bär K, Weiler M, Bodamer J, et al. Extrakorporale Stosswellentherapie (ESWT)-Eine Möglichkeit zur Therapie der Podotrochlose. Tierarztl Prax 2001;29:163-167.

4. Löffeld S, Boening K-J, Weitkamp K, et al. Radiale extrakorporale Stosswellentherapie bei Pferden mit chronischer Insertionsdesmopathie am Fesselträgerursprung--Eine kontrollierte Studie. Pferdeheilk 2002;18:147-154.

5. Schnewlin M, Lischer C. Extracorporal shock wave therapy in veterinary medicine [in German]. Schweiz Arch Tierheilkd $2001 ; 143: 227-232$

6. Melzack R. Prolonged relief of pain by brief, intense transcutaneous somatic stimulation. Pain 1975;1:357-373.

7. Rompe JD, Kullmer K, Vogel J, et al. Extracorporeal shockwave therapy. Experimental basis, clinical application [in German] Orthopade 1997;26:215-228.

8. Haake $M$, Thon A, Bette M. Absence of spinal response to extracorporeal shock waves on the endogenous opioid systems in the rat. Ultrasound Med Biol 2001;27:279-284.

9. Haake M, Thon A, Bette M. No influence of low-energy extracorporeal shock wave therapy (ESWT) on spinal nociceptive systems. J Orthop Sci 2002;7:97-101.

10. Takahashi N, Wada Y, Ohtori S, et al. Application of shock waves to rat skin decreases calcitonin gene-related peptide immunoreactivity in dorsal root ganglion neurons. Auton Neurosci 2003; 107:81-84.

11. Haake $M$, Thon A, Bette $M$. Unchanged c-Fos expression after extracorporeal shock wave therapy: an experimental investigation in rats. Arch Orthop Trauma Surg 2002;122:518-521.

12. Schelling G, Delius M, Gschwender M, et al. Extracorporeal shock waves stimulate frog sciatic nerves indirectly via a cavitationmediated mechanism. Biophys J 1994;66:133-140.

13. Young RR, Henneman E. Functional effects of focused ultrasound on mammalian nerves. Science 1961;134:1521-1522.

14. Dahmen GP, Nam VC, Meiss L. Extrakorporale Stosswellentherapie zur Behandlung von knochennahen Weichteilschmerzen: Indikation, Technik und vorläufige Ergebnisse. In: Chaussy $C$, Eisenberger $F$, Jocham D, et al, eds. Stosswellenlithotripsie-Aspekte und Prognosen. Tübingen, Germany: Attempto Verlag, 1993;143-148.

15. Fédération Equestre Internationale. Alternative treatment of horses at FEI events. In: Veterinary regulations. 9th ed. Lausanne, Switzerland: Fédération Equestre Internationale, 2002;34.

16. Stashak TS. Diagnosis of lameness. In: Stashak TS, ed. Adams' lameness in horses. 4th ed. Philadelphia: Lea \& Febiger, 1987;134-139.

17. McClure SR, VanSickle D, Evans R, et al. The effects of extracorporeal shock-wave therapy on the ultrasonographic and histologic appearance of collagenase-induced equine forelimb suspensory ligament desmitis. Ultrasound Med Biol 2004;30:461-467.

18. Crowe OM, Dyson SJ, Wright IM, et al. Treatment of chronic or recurrent proximal suspensory desmitis using radial pressure wave therapy in the horse. Equine Vet J 2004;36:313-316.

19. Sack WO. Nerve distribution in the metacarpus and front digit of the horse. J Am Vet Med Assoc 1975;167:298-305.
20. Pohlmeyer K, Redecker R. Clinically significant nerves in the limbs of horses including possible variants [in German]. Dtsch Tierarztl Wochenschr 1974;81:501-505.

21. Grau H. Die Hautinnervation an den Gliedmassen des Pferdes. Arch Tierheilk 1935;69:96-116.

22. Nickel R, Schummer A, Seiferle E. Armgeflecht. Plexus brachialis und Nerven der Vordergliedmasse. In: Boehme G, ed. Lehrbuch der Anatomie der Haustiere: Nervensystem, Sinnesorgane, Endokrine Drüsen. 4th ed. Stuttgart, Germany: Parey Verlag, 2004;241-260.

23. Laitinen LV, Eriksson AT. Electrical stimulation in the measurement of cutaneous sensibility. Pain 1985;22:139-150.

24. Notermans SL. Measurement of the pain threshold determined by electrical stimulation and its clinical application. I. Method and factors possibly influencing the pain threshold. Neurology 1966;16:1071-1086.

25. Wang GH. The galvanic skin reflex: a review of old and recent works from a physiologic point of view I. Am J Phys Med 1957;36:295-320.

26. Ludin HP. Reflex examinations. In: Electromyography in practice. Stuttgart, Germany: Georg Thieme Verlag, 1980;45-47.

27. McClure S, Yeager A, Amin V. Safety of extracorporeal shock wave therapy in performance horses, in Proceedings. Am Assoc Equine Pract Annu Meet 2003;49:62-65.

28. Bolt DM, Burba DJ, Hubert JD, et al. Determination of functional and morphologic changes in palmar digital nerves after nonfocused extracorporeal shock wave treatment in horses. Am J Vet Res 2004:65:1714-1718.

29. Bolt DM, Burba DJ, Hubert JD, et al. Evaluation of cutaneous analgesia after non-focused extracorporeal shock wave application over the 3rd metacarpal bone in horses. Can J Vet Res 2004;68:288-292.

30. McClure SR, Merritt DK. Extracorporeal shock-wave therapy for equine muskuloskeletal disorders. Compend Contin Educ Pract Vet 2003;25:68-75.

31. Van Hoogmoed L, Snyder JR, Allen AK, et al. Use of infrared thermography to detect performance-enhancing techniques in horses. Equine Vet Educ 2000;12:102-107.

32. Van Hoogmoed L, Snyder JR. Use of infrared thermography to detect injections and palmar digital neurectomy in horses. Vet $J$ 2002;164:129-141.

33. Ringer S, Lischer C, Ueltschi G. Assessment of scintigraphic and thermographic changes after focused extracorporeal shock wave therapy on the origin of the suspensory ligament and the fourth metarsal bone in horses without lameness. Am J Vet Res 2005;66:1836-1842.

34. Kamerling S, Wood T, DeQuick D, et al. Narcotic analgesics, their detection and pain measurement in the horse: a review. Equine Vet J 1989;21:4-12.

35. Moens Y, Lanz F, Doherr MG, et al. A comparison of the antinociceptive effects of xylazine, detomidine, and romifidine on experimental pain in horses. Vet Anaesth Analg 2003;30:183-190.

36. Schatzman U, Armbruster S, Stucki F, et al. Analgesic effect of butorphanol and levomethadone in detomidine sedated horses. $J$ Vet Med A Physiol Pathol Clin Med 2001;48:337-342.

37. Hamm D, Turchi P, Jochle W. Sedative and analgesic effects of detomidine and romifidine in horses. Vet Rec 1995;136:324-327.

38. Pippi NL, Lumb WV. Objective tests of analgesic drugs in ponies. Am J Vet Res 1979;40:1082-1086.

39. Spadavecchia C, Spadavecchia L, Andersen OK, et al. Quantitative assessment of nociception in horses by use of the nociceptive withdrawal reflex evoked by transcutaneous electrical stimulation. Am J Vet Res 2002;63:1551-1556.

40. Bolz W. Versuche zur Feststellung der Anästhesiegebiete nach örtlicher Betäubung der Zehennerven beim Pferde. Tierärztl Rundsch 1932;7:119-121.

41. Schatzmann U. Sedation des stehenden Pferdes. In: Schatzman U, ed. Sedation und Anästhesie des Pferdes. Berlin: Blackwell Wissenschafts-Verlag, 1995;69-84.

42. Graham BA, Hammond DL, Proudfit HK. Differences in the antinociceptive effects of alpha-2 adrenoceptor agonists in two substrains of Sprague-Dawley rats. J Pharmacol Exp Ther 1997;283:511-519. 


\section{Curriculum vitae}

\section{PERSÖNLICHE DATEN}

\begin{tabular}{ll}
\hline & \\
Familienname: & Waldern \\
Vorname: & Nina \\
Geburtsdatum: & 25.05 .1977 \\
Geburtsort: & Karlsruhe (Deutschland), \\
Nationalität: & Deutsch \\
Wohnort: & Wasterkingen $(\mathrm{ZH}$, Schweiz)
\end{tabular}

\section{AUSBILDUNG}

\section{Schulbildung:}

1984- 1988 Grund- und Hauptschule Grötzingen

1988- 1989 Ludwig- Marum- Gymnasium Pfinztal- Berghausen

1989- 1997 Markgrafengymnasium Durlach, Zeugnis der Allgemeinen Hochschulreife

\section{Studium:}

1997- 2003 Studium der Veterinärmedizin an der Justus- Liebig- Universität Giessen, Deutschland

$1998 \quad$ Vorphysikum

1999 Physikum; naturwissenschaftlicher Abschnitt der vorklinischen Prüfung

1999- 2000 Ecole Nationale Vétérinaire de Nantes, Erasmus- Programm, Frankreich

2001 1. Abschnitt der Tierärztlichen Prüfung

2001 2. Abschnitt der Tierärztlichen Prüfung

2002 3. Abschnitt der Tierärztlichen Prüfung und Tierärztliche Approbation 
12/2003 Vertretungsstelle in der Kleintierpraxis Dr. Andrea Becker, Wellendingen, Deutschland

01- 07/ 2004 50\% Assistentenstelle im Sportmedizinischen Leistungszentrum der Pferdeklinik der Vetsuisse- Fakultät, Universität Zürich, Schweiz

08/2004-07/2005 Jahresstipendium für Doktoranden des Deutschen Akademischen Austausch Dienstes (DAAD) im Sportmedizinischen Leistungszentrum der Pferdeklinik der Vetsuisse- Fakultät, Universität Zürich, Schweiz

seit 08/ 2005 Assistenzstelle im Sportmedizinischen Leistungszentrum der Pferdeklinik der VetsuisseFakultät, Universität Zürich, Schweiz

Zürich, den 21.12.2005 